\title{
An Evaluation of the Antibacterial, Anti-Giardial, Anticancer and Toxicity Properties of Selected Nut Extracts
}

\author{
Pauline Lebaratoux ${ }^{1,2^{*}}$, Joseph Sirdaarta ${ }^{1,3^{*}}$, Paran Rayan ${ }^{1,3^{*}}$, Pauline Ann McDonnell ${ }^{1 *}$, Ian Edwin Cock ${ }^{1,3^{*}}$ \\ 'School of Natural Sciences, Griffith University, 170 Kessels Rd, Nathan, Queensland 4111, AUSTRALIA. \\ ${ }^{2}$ School of Biology, Ecole de Biologielndustrielle (EBI), Cergy, FRANCE. \\ ${ }^{3}$ Environmental Futures Research Institute, Nathan Campus, Griffith University, 170 Kessels Rd, Nathan, Queensland 4111, AUSTRALIA.
}

\begin{abstract}
Background: Foods with high oil and fatty acid contents have been linked with a variety of medicinal properties including bacterial growth inhibition, anti-Giardial activity and the inhibition of cancer cell proliferation. Almond, cashew, hazelnut and walnut contain very high fatty acid contents. Despite this, these nuts have not been adequately screened for medicinal properties. Materials and Methods: Almond, cashew, hazelnut and walnut powders were extracted and tested for antimicrobial activity using modified disc diffusion and MIC methods. Inhibitory activity against the gastrointestinal protozoal parasite Giardia duodenalis and against $\mathrm{CaCo} 2$ cancer cells were evaluated using colorimetric cell proliferation assays. Toxicity was evaluated using an Artemia franciscana nauplii bioassay. Results: The methanolic almond and walnut solvent extractions displayed broad spectrum growth inhibitory activity, inhibiting the growth of $100 \%$ and 7 of the $11(64 \%)$ bacterial strains tested respectively. The methanolic walnut extract was a particularly potent growth inhibitor, with MIC values of $\sim 1000 \mu \mathrm{g} / \mathrm{mL}$, $700 \mu \mathrm{g} / \mathrm{mL}$ and $800 \mu \mathrm{g} / \mathrm{mL}$ against $A$. baylyi, P. mirabilis and $P$. vulgaris respectively. The methanolic almond extract also had moderate to inhibitory activity against $E$. coli (MIC $\sim 2000 \mu \mathrm{g} / \mathrm{mL}$ ), P. mirabilis and P. vulgaris (both $\sim 2500 \mu \mathrm{g} / \mathrm{mL}$ ). The methanolic cashew and hazelnut extracts were moderate inhibitors of $E$. coligrowth ( 2500 and $1250 \mu \mathrm{g} / \mathrm{mL}$ respectively). The meth-
\end{abstract}

anolic almond extract was also a potent inhibitor of $G$. duodenalis proliferation $\left(I C_{50} 878 \mu \mathrm{g} / \mathrm{mL}\right)$. All extracts were ineffective at blocking the growth of the colorectal cancer cell line $\mathrm{CaC}$ 2. Instead, most of the extracts substantially stimulated proliferation. All of the nut extracts were non-toxic in the Artemia nauplii bioassay. Conclusion: The bacterial growth inhibitory activities of the methanolic almond and walnut extracts, the anti-Giardial activity of the methanolic almond extract and their lack of toxicity indicates the potential of these extracts in the discovery and development of new natural antibiotic agents

Key words: Antibacterial activity, Giardia duodenalis, Anti-proliferative activity, CaCo2, Anticancer activity, Artemia, Toxicity.

\section{Correspondence:}

Ian Edwin Cock, School of Natural Sciences, Griffith University,

170 Kessels Rd, Nathan, Queensland 4111, AUSTRALIA.

Tel.: +61 7 37357637; fax: +61 737355282 .

E-mail: I.Cock@griffith.edu.au (I. E. Cock)

DOI : $10.5530 /$ pc.2016.3.7

\section{INTRODUCTION}

Plant materials have been used for thousands of years to treat a variety of different diseases and medical complaints by most, if not all civilisations internationally. Edible plants which contain biologically active compounds or with documented health benefits are particularly useful as they provide both nutritional and therapeutic benefits. The medicinal properties of many culinary herbs have been extensively documented and many of these are also used as traditional medicines. Indeed, the highly spiced nature of Indian cuisine and Ayurveda are intertwined. ${ }^{1}$ Ayurvedic practitioners focus on disease prevention and holistic health promotion, with an emphasis on the diet. A large number of herbs and spices are common between Ayurveda and Indian cooking. For example, turmeric (a curry component) is used in Auyverda to treat jaundice, basil is used as a cardio-protectant, cinnamon for circulatory disorders, mace for gastric infections and ginger as a universal medicine for a wide variety of complaints. Similarly, herbs and spices used in other Asian, European, African and Australian cuisines as well as food from the Americas have also been used medicinally. Scientific investigation has verified the therapeutic potential of many of these. Curcumin has been identified as an anticancer component of turmeric. ${ }^{2}$ Garlic, green tea, rosemary, sage, thyme and saffron have been linked with a reduction of blood cholesterol, immunomodulatory and anticancer activity. ${ }^{3}$ Several native Australian culinary herbs inhibit the early phases of autoimmune inflammatory disease. ${ }^{4}$

Recently, attention has also focussed on the therapeutic potential of fruits and berries with high antioxidant contents. The bacterial growth inhibitory properties of many fruit have been particularly well reported..$^{5-9}$
Indeed, these studies have highlighted several high antioxidant fruits as having particular interest, with MIC values for the crude extracts similar to those of conventional antibiotics. Several of the same high antioxidant fruits also have potent anti-Giardial ${ }^{10,11}$ and anticancer activities. ${ }^{12}$ Despite the relative wealth of information on the medicinal and functional food properties of foliage, fruits and berries, there has been relatively few studies examining the therapeutic potential of edible nuts. Recent studies have reported the therapeutic potential of Macadamia integriflora nuts (commonly known as macadamia nuts, baupe nuts, Queensland nuts). Growth inhibitory activity of $M$. integriflora nuts, ${ }^{13}$ as well as leaves and flowers ${ }^{14,15}$ against a broad panel of bacteria and fungi has been reported. A noteable feature of macadamia nuts is their high fat contents (estimated to be as high as $76 \%$ of total mass), with especially high contents of the beneficial mono-saturated fats and omega-7 palmitoleic acid, ${ }^{16}$ which have been shown to decrease plasma cholesterol levels. ${ }^{17}$ Furthermore, the high palmitoleic acid levels and the oxidative stability of $M$. integriflora nut oil make it a desirable component of cosmetics and skin care products. ${ }^{16,18}$ The nuts also contain vitamins A1, E, B1, B2 and niacin in significant quantities. ${ }^{16}$ Recent studies have reported antibacterial and growth inhibitory properties for these fats against the gastrointestinal protozoal parasite Giardia duodenalis. ${ }^{10,11}$ As G. duodenalis are unable to adequately metabolise medium chain saturated fatty acids, it is believed that they accumulate in cytoplasmic vesicles until the cells eventually rupture, resulting in G. duodenalis mortality. ${ }^{10}$

Many other nuts are also used extensively for their taste and nutritional properties. Several of these nuts also rich sources of mono-unsaturated 
and saturated fats and thus may have similar antibacterial and antiGiardial properties to those reported for macadamia nuts. The nut from Prunus dulcis Miller (commonly known as almond) is a nutritionally dense food and a rich source of vitamin E. Indeed vitamin E levels as high as $20 \mathrm{mg}$ per $100 \mathrm{~g}$ of nuts has been reported. ${ }^{19}$ Almond nuts also contain substantial levels of phytosterols including $\beta$-sitosterol, staigmasterol, campesterol and sitostanol. ${ }^{20}$ All of these compounds have been associated with cholesterol lowering properties. ${ }^{21}$ Anacardium occidentale L. seeds (cashew nut) are another nutritious and tasty food. Cashews are known for their high starch content $(\sim 25 \%$ of the nut weight). ${ }^{22}$ Although they have lower fat contents than macadamia nuts ( $40 \%$ compared to up to $60 \%$ for macadamia nuts), ${ }^{16,20,23}$ cashew nuts are also a rich source of fats and oils. The levels of medium and long chain mono-unsaturated and poly-unsaturated fatty acids are particularly high. ${ }^{23}$ The nut also has a relatively high antioxidant capacity and is a good source of the dietary minerals copper, manganese, magnesium and phosphorus. Corylus avellana L. (hazelnut, cobnut, fiber nut) are rich in protein and unsaturated fats. ${ }^{20}$ The nut also contains significant levels of vitamins $\mathrm{B} 1$ and $\mathrm{B} 6$, and is high in fibre. Juglans regia $\mathrm{L}$. (common walnut, English walnut, Persian walnut) is a nutrient rich food containing high levels of protein ( 20 g/100 g nut), total fats ( $\sim 50 \mathrm{~g} / 100 \mathrm{~g}$ nut $)$ and fiber $\left(\sim 7 \mathrm{~g} / 100 \mathrm{~g}\right.$ nut). ${ }^{24}$ Unlike the other nuts whose fat contents consist largely of mono-unsaturated fatty acids, walnut oils are comprised mainly of poly-unsaturated fatty acids ( $~ 70 \%$ of total fats). ${ }^{20}$ The levels of $\alpha$-linolenic acid are particularly high. Linolenic acid is effective in reducing the risk of coronary disease, blocking inflammation and decreasing nitric oxide synthase gene expression via NF- $\kappa B$ and mitogen activated protein kinase (MAPK) pathways, resulting in inhibition of nitric oxide production. ${ }^{25}$ Thus it is possible that linolenic acid may also have anticancer affects.

The current study was undertaken to test almond, cashew, hazelnut and walnut extracts for the ability to inhibit microbial growth against a panel of pathogenic bacteria. The extracts were also tested for the ability to inhibit the growth of the gastro-intestinal protozoal parasite G. duodenalis. Through examining the antimicrobial capability of the nut extracts, their potential as inhibitors of bacterial and protozoal pathogens was assessed. Furthermore, the ability of the nut extracts to block proliferation of the colorectal carcinoma cell line $\mathrm{CaCo} 2$ was also examined. Toxicity screening was used to evaluate the safety of the nut extracts.

\section{MATERIALS AND METHODS}

Vacuum sealed organic almond meal, whole raw organic cashews, organic hazelnut meal and raw walnut halves was obtained from NSM food suppliers, Australia. The nuts and nut meal were processed in a Sunbeam food dehydrator to ensure that they were thoroughly dehydrated and the nut pieces were subsequently ground into a coarse powder. The powdered nut meals were extracted by standardised methods. ${ }^{26,27}$ Briefly, an amount of $2 \mathrm{~g}$ of each nut meal was weighed into each of five tubes and five different extracts were prepared by adding $50 \mathrm{~mL}$ of methanol, water, ethyl acetate, chloroform, or hexane respectively. All solvents were obtained from Ajax Chemicals, Australia and were AR grade. The nut meals were individually extracted in each solvent for 24 hours at $4^{\circ} \mathrm{C}$ with gentle shaking. The extracts were subsequently filtered through filter paper (Whatman No. 54) under vacuum, followed by drying by rotary evaporation in an Eppendorf concentrator 5301. The dry extract was weighed and redissolved in $10 \mathrm{~mL}$ deionised water (containing $1 \%$ DMSO).

\section{Qualitative phytochemical studies}

Phytochemical analysis of the nut extracts for the presence of saponins, phenolic compounds, flavonoids, phytosterols, triterpenoids, cardiac glycosides, anthraquinones, tannins and alkaloids was conducted by previously described assays. ${ }^{28-30}$

\section{Antibacterial screening}

\section{Test microorganisms}

All media was supplied by Oxoid Ltd., Australia. Reference strains of Acinitobacter baylyi (ATCC33304), Escherichia coli (ATCC0157), Klebsiella pneumoniae (ATCC31488), Proteus mirabilis (ATCC21721), Proteus vulgaris (ATCC21719) and Pseudomonas aeruginosa (ATCC39324) were purchased from American Tissue Culture Collection, USA. All other clinical microbial strains were obtained from the School of Natural Sciences teaching laboratory, Griffith University. All stock cultures were subcultured and maintained in nutrient broth at $4^{\circ} \mathrm{C}$.

\section{Evaluation of antimicrobial activity}

Antimicrobial activity of all nut extracts was determined using a modified disc diffusion method. ${ }^{31-33}$ Briefly, $100 \mu \mathrm{L}$ of the test bacteria were grown in $10 \mathrm{~mL}$ of fresh nutrient broth until they reached a count of approximately $10^{8}$ cells $/ \mathrm{mL}$ as determined by direct microscopic determination. One hundred microliters of microbial suspension was spread onto the nutrient agar plates. The extracts were tested using $5 \mathrm{~mm}$ sterilised filter paper discs. Discs were infused with $10 \mu \mathrm{L}$ of the test sample, allowed to dry and placed on to the inoculated plates. The plates were allowed to stand at $4^{\circ} \mathrm{C}$ for 2 hours before incubation with the test microbial agents. Plates inoculated with A.baylyi, K. pneumoniae, P. mirabilis, $P$. vulgaris and $P$. aeruginosa were incubated at $30^{\circ} \mathrm{C}$ for 24 hours, then the diameters of the inhibition zones were measured in millimetres. Plates inoculated with E. coli were incubated at $37^{\circ} \mathrm{C}$ for 24 hours, then the diameters of the inhibition zones were measured. All measurements were to the closest whole millimetre. Each antimicrobial assay was performed in at least triplicate and mean values were determined. Standard discs of ampicillin $(2 \mu \mathrm{g})$ were obtained from Oxoid Ltd., Australia and served as a positive control for antibacterial activity. Filter discs infused with $10 \mu \mathrm{L}$ of distilled water were used as negative controls.

\section{Minimum inhibitory concentration (MIC) determination}

The minimum inhibitory concentration (MIC) of the nut extracts were determined by the disc diffusion method ${ }^{34,35}$ The plant extracts were diluted in deionised water (containing 1\% DMSO) then discs were infused with $10 \mu \mathrm{L}$ of the test dilutions, allowed to dry and placed onto inoculated plates. The assay was performed as outlined above and graphs of the zone of inhibition versus concentration were plotted for each extract. Linear regression was used to calculate the MIC values.

\section{Inhibitory bioactivity against Giardia duodenalis trophozoites}

\section{Parasite culture}

The Giardia duodenalis S-2 (sheep strain 2) trophozoite strain used in this study was previously supplied by Professor Andre Buret, University of Calgary, Canada. G. duodenalis tropozoites were maintained and subcultured anaerobically at $37^{\circ} \mathrm{C}$ in TYI-S-33 growth media supplemented with 1\% bovine bile (Sigma), 10\% Serum Supreme (Cambrex Bioproducts) and $200 \mathrm{IU} / \mathrm{mL}$ penicillin $/ 200 \mu \mathrm{g} / \mathrm{mL}$ streptomycin (In vitro gen, USA). Confluent mid log phase cultures were passaged every 2 days by chilling the cultures on ice for a minimum of $10 \mathrm{~min}$, followed by vortexing to dislodge the adherent trophozoites from the walls of the culture vessel. Fresh culture media $(5 \mathrm{~mL})$ was seeded with approximately $1 \times 10^{5}$ trophozoites for each passage. 
Table 1: The mass of dried extracted nut meal, the concentration of extracts after resuspension in deionised water and qualitative phytochemical screenings of solvent extractions

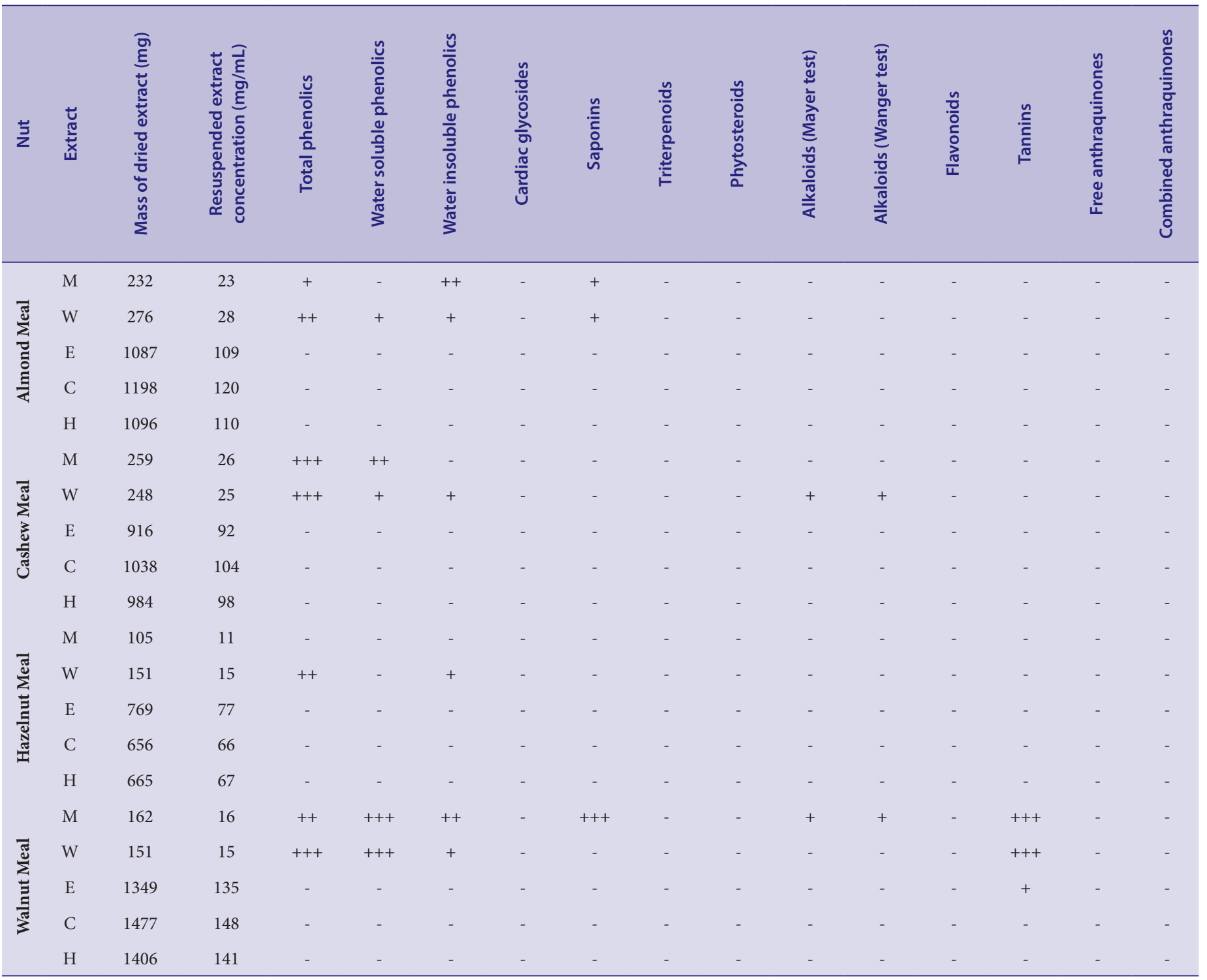

+++ indicates a large response; ++ indicates a moderate response; + indicates a minor response; - indicates no response in the assay; $\mathrm{M}=$ methanolic extract; $\mathrm{W}=$ aqueous extract; $\mathrm{E}=$ ethyl acetate extract; $\mathrm{C}=$ chloroform extract; $\mathrm{H}$ = hexane extract.

\section{Evaluation of anti-Giardial activity}

Screening for anti-Giardia activity was performed by a modified colorimetric method. ${ }^{10,36}$ Briefly, confluent cultures were chilled on ice for a minimum of $10 \mathrm{~min}$, followed by vortexing to dislodge the adherent trophozoites. Aliquots of the trophozoite suspension $(70 \mu \mathrm{L})$ containing approximately $1 \times 10^{5}$ trophozoites were added to the wells of a 96 well plate. A volume of $30 \mu \mathrm{L}$ of the test extracts or the vehicle solvent or culture media (for the negative controls) was added to individual wells and the plates were incubated anaerobically at $37^{\circ} \mathrm{C}$ for 12 hours in a humidified anaerobic atmosphere. A volume of $20 \mu \mathrm{L}$ of Cell Titer $96^{\circ}$ AQueous One Solution Cell Proliferation Assay Reagent (Promega) was subsequently added to each well and the plates were incubated for a further 3 hours. Absorbances were recorded at $490 \mathrm{~nm}$ using a Molecular Devices, Spectra Max M3 plate reader. All tests were performed in at least triplicate and triplicate controls were included on each plate.
The anti-proliferative activity of each test was calculated as a percentage of the negative control using the following formula:

$$
\text { Giardial growth (\% untreated control })=(\text { Act } / A c c) \times 100
$$

$\mathrm{A}_{\mathrm{ct}}$ is the corrected absorbance for the test extract (calculated by subtracting the absorbance of the test extract in media without cells from the extract/cell/test combination) and $\mathrm{A}_{c \mathrm{cc}}$ is the corrected untreated control (calculated by subtracting the absorbance of the untreated control in media without cells from the untreated cell media combination).

\section{Screen for anti-cancer bioactivity}

\section{Colorectal carcinoma cell line}

The CaCo2 carcinoma cells used in this study were obtained from American Type Culture Collection (Rockville, USA). The cells were cultured in 


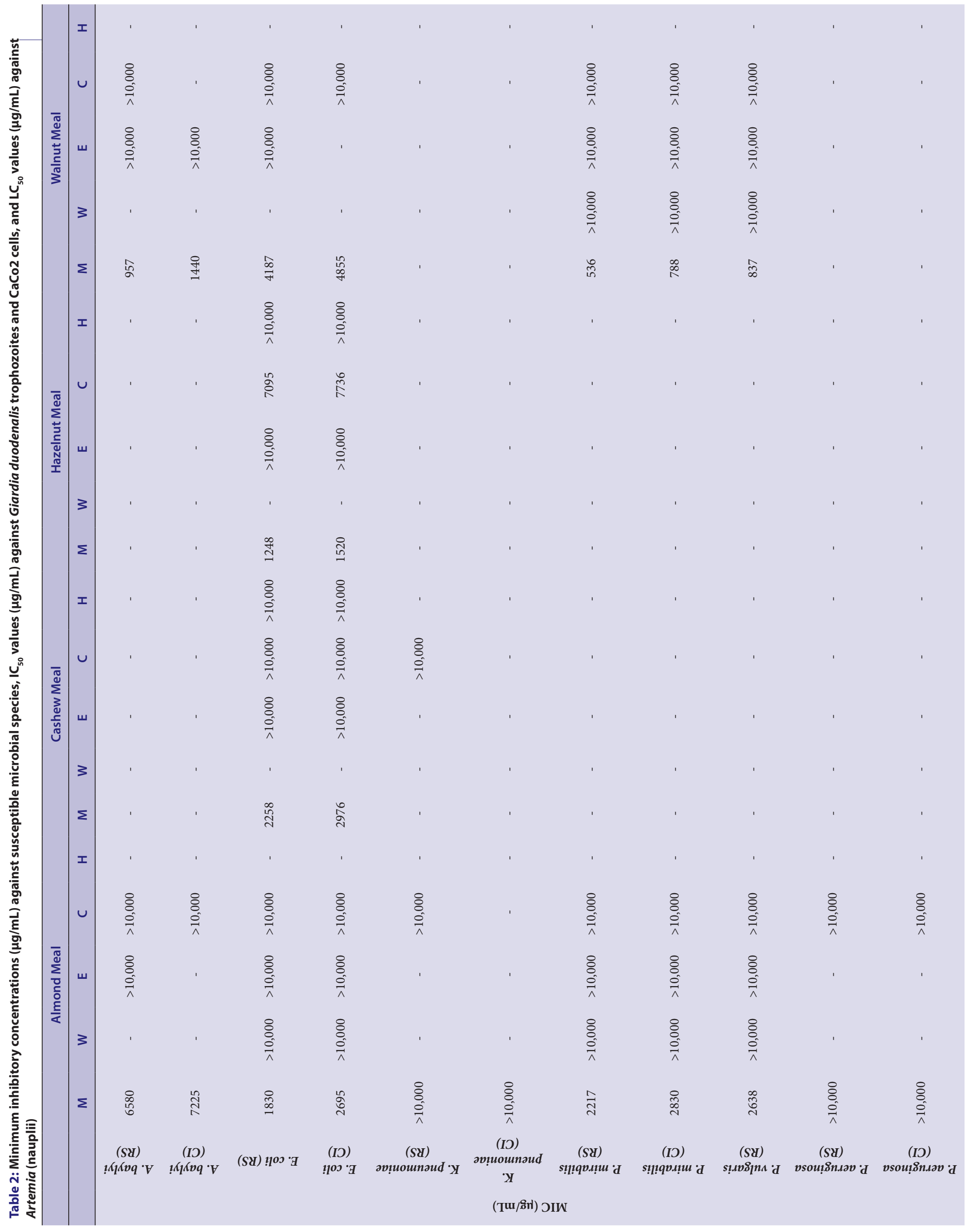




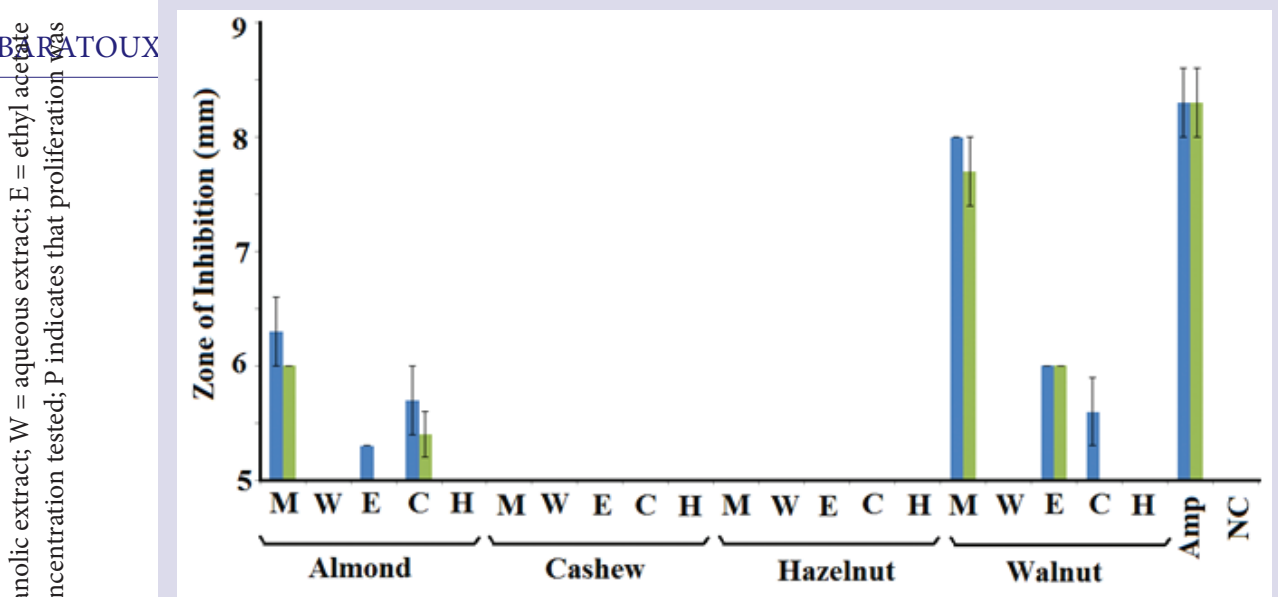

Figure 1: Antibacterial activity of the nut meal extracts and an ampicillin control $(2 \mu \mathrm{g})$ measured as zones of inhibition $(\mathrm{mm})$ against $A$. baylyi. Blue bars represent inhibition zones of reference bacterial strain (ATCC33304); green bars represent inhibition zones of clinical bacterial strain; $\mathrm{M}=$ methanolic extract; $\mathrm{W}=$ aqueous extract; $\mathrm{E}=$ ethyl acetate extract; $\mathrm{C}=$ chloroform extract; $\mathrm{H}=$ hexane extract. Results are expressed as mean \pm SEM of at least triplicate determinations.

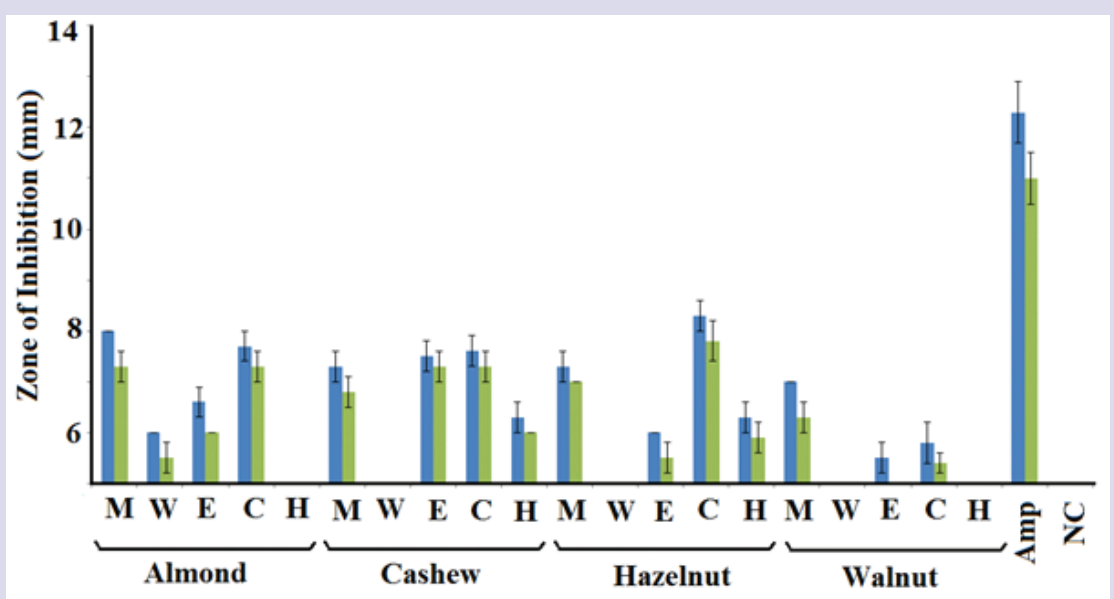

Figure 2: Antibacterial activity of the nutmeal extractsand an ampicillin control $(2 \mu \mathrm{g})$ measured as zones of inhibition $(\mathrm{mm})$ against $E$. coli. Blue bars represent inhibition zones of reference bacterial strain (ATCC0157); green bars represent inhibition zones of clinical bacterial strain; $M=$ methanolic extract; $\mathrm{W}=$ aqueous extract; $\mathrm{E}=$ ethyl acetate extract; $\mathrm{C}=$ chloroform extract; $\mathrm{H}=$ hexane extract. Results are expressed as mean \pm SEM of at least triplicate determinations.

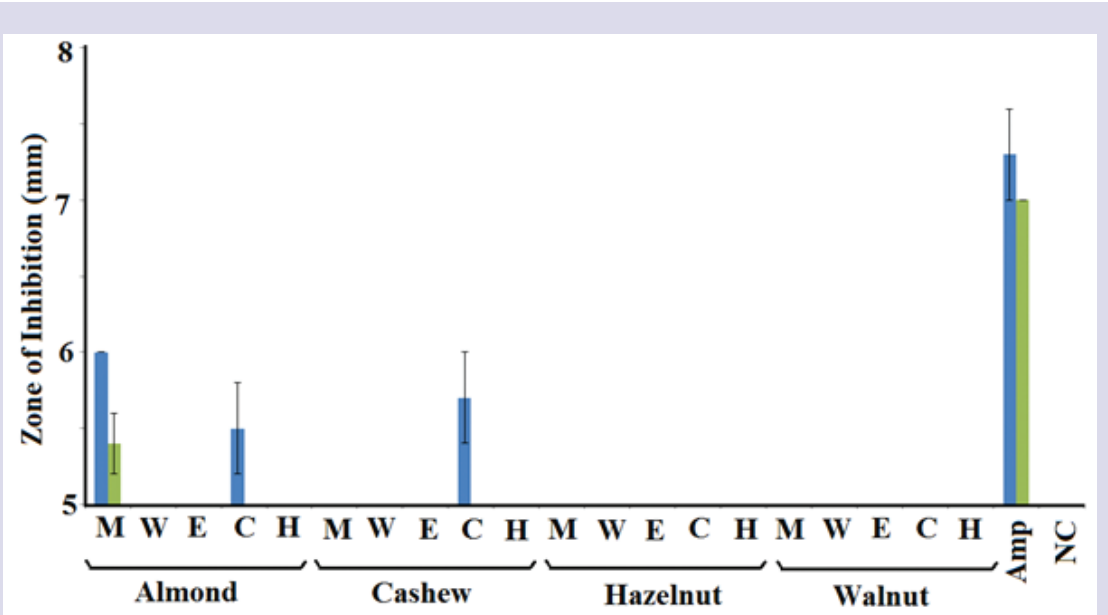

Figure 3: Antibacterial activity of the nutmeal extracts and an ampicillin control $(2 \mu \mathrm{g})$ measured as zones of inhibition $(\mathrm{mm})$ against $K$. pneumoniae. Blue bars represent inhibition zones of reference bacterial strain (ATCC31488); green bars represent inhibition zones of clinical bacterial strain; $\mathrm{M}=$ methanolic extract; $\mathrm{W}=$ aqueous extract; $\mathrm{E}=$ ethyl acetate extract; $\mathrm{C}=$ chloroform extract; $\mathrm{H}=$ hexane extract. Results are expressed as mean \pm SEM of at least triplicate determinations. 


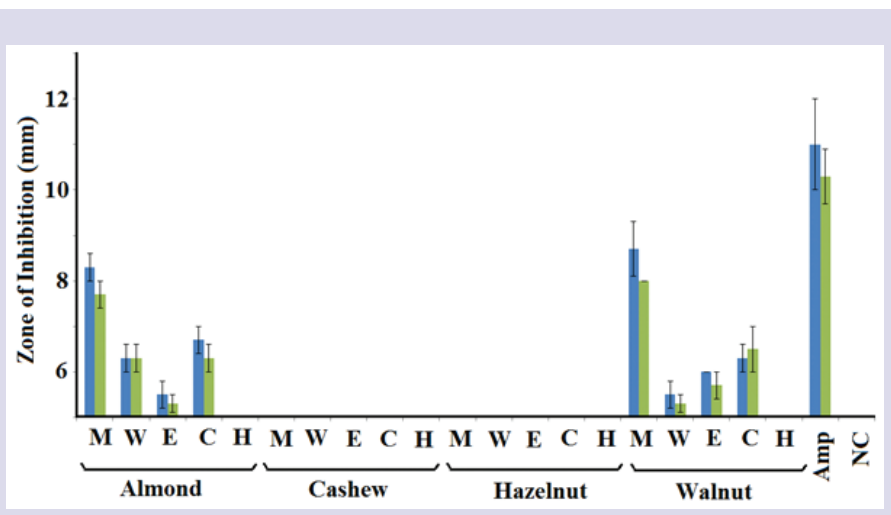

Figure 4: Antibacterial activity ofthe nutmeal extracts and an ampicillin control $(2 \mu \mathrm{g})$ measured as zones of inhibition $(\mathrm{mm})$ against $P$. mirabilis. Blue bars represent inhibition zones of reference bacterial strain (ATCC21721); green bars represent inhibition zones of clinical bacterial strain; $M=$ methanolic extract; $W=$ aqueous extract; $E=$ ethyl acetate extract; $C=$ chloroform extract; $\mathrm{H}=$ hexane extract. Results are expressed as mean \pm SEM of at least triplicate determinations.

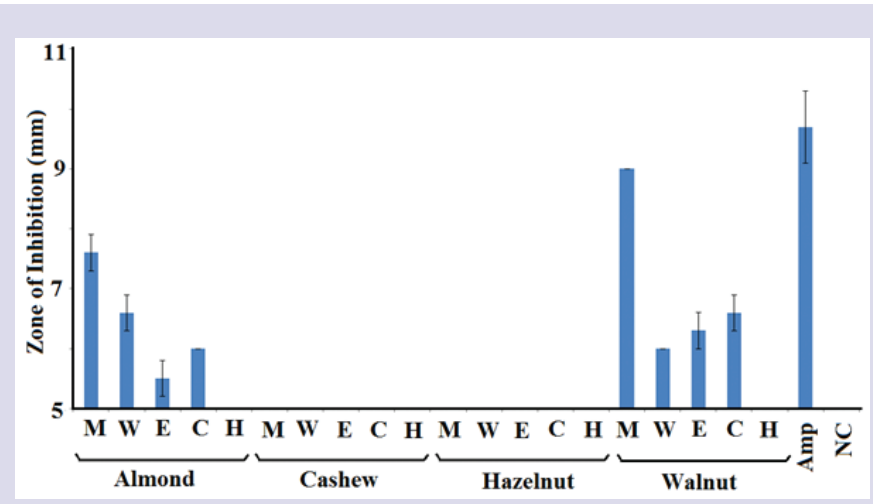

Figure 5: Antibacterial activity of the nutmeal extracts and an ampicillin control $(2 \mu \mathrm{g})$ measured as zones of inhibition $(\mathrm{mm})$ against $P$. vulgaris. $M=$ methanolic extract; $W=$ aqueous extract; $E=$ ethyl acetate extract; $C=$ chloroform extract; $\mathrm{H}=$ hexane extract. Results are expressed as mean $\pm \mathrm{SEM}$ of at least triplicate determinations.

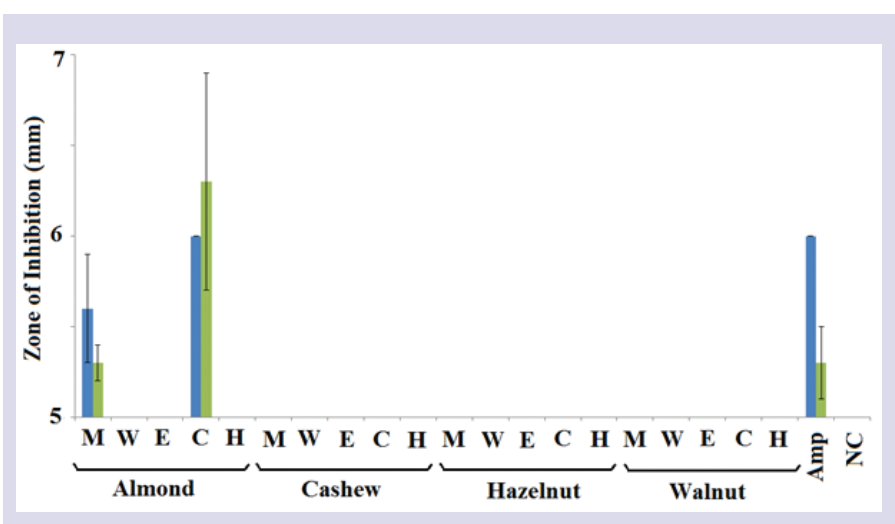

Figure 6: Antibacterial activity of the nutmeal extracts and an ampicillin control $(2 \mu \mathrm{g})$ measured as zones of inhibition $(\mathrm{mm})$ against $P$. aeruginosa. Blue bars represent inhibition zones of reference bacterial strain (ATCC39324); green bars represent inhibition zones of clinical bacterial strain; $M=$ methanolic extract; $\mathrm{W}=$ aqueous extract; $\mathrm{E}=$ ethyl acetate extract; $\mathrm{C}=$ chloroform extract; $\mathrm{H}=$ hexane extract. Results are expressed as mean \pm SEM of at least triplicate determinations.

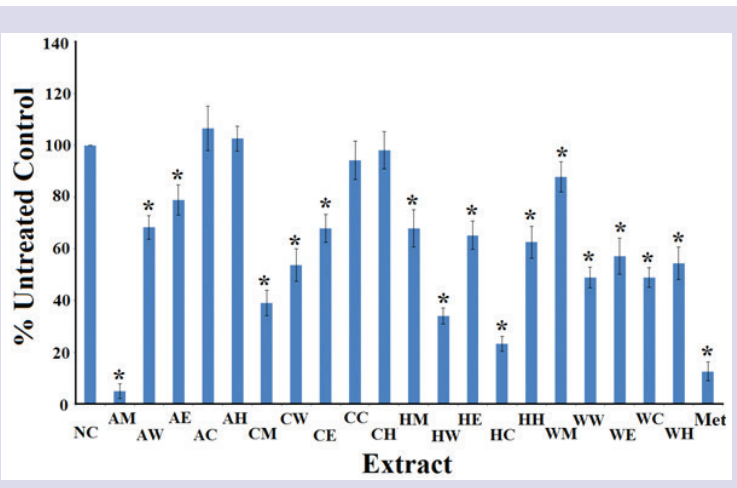

Figure 7: Inhibitory activity of the nutmeal extracts against $\mathrm{G}$. duodenalis trophozoites measured as a percentage the untreated control $\mathrm{AM}=$ methanolic almond extract; $\mathrm{AW}=$ aqueous almond extract; $\mathrm{AE}=$ almond ethyl acetate extract; $\mathrm{AC}=$ chloroform almond extract; $\mathrm{AH}=$ hexane almond extract; $\mathrm{CM}=$ methanolic cashew extract; $\mathrm{CW}=$ aqueous cashew extract; $\mathrm{CE}=$ ethyl acetate cashew extract; $\mathrm{CC}=$ chloroform cashew extract; $\mathrm{CH}=$ hexane cashew extract; $\mathrm{HM}=$ methanolic hazelnut extract; $\mathrm{HW}=$ aqueous hazelnut extract; $\mathrm{HE}=$ ethyl acetate hazelnut extract; $\mathrm{HC}=$ chloroform hazelnut extract; $\mathrm{HH}=$ hexane hazelnut extract; $\mathrm{WM}=$ methanolic walnut extract; $\mathrm{WW}=$ aqueous walnut extract; $W E=$ ethyl acetate walnut extract; $W C=$ chloroform walnut extract; $\mathrm{WH}=$ hexane walnut extract; Met $=$ metronidazole $(50 \mu \mathrm{g} / \mathrm{ml}) .{ }^{*}$ indicates results that are significantly different to the untreated control $(p<0.01)$.

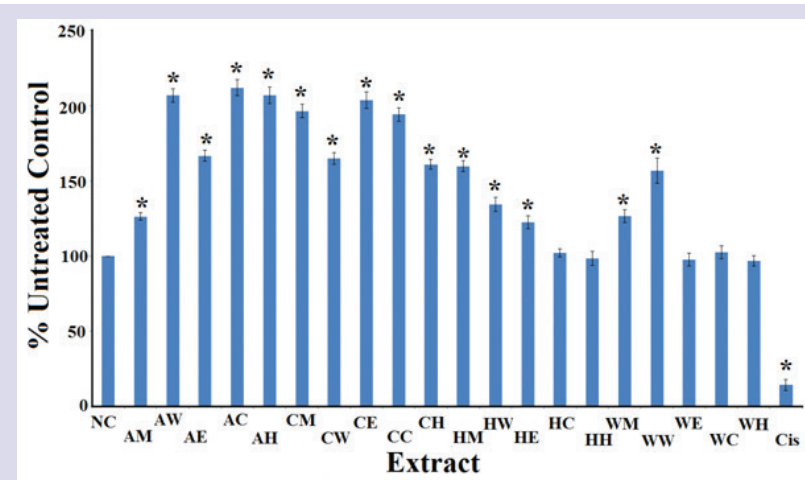

Figure 8: Anti-proliferative activity of the nutmeal extracts and untreated controls against $\mathrm{CaCo} 2$ cancer cell lines measured as percentages of the untreated control cells. $\mathrm{AM}=$ methanolic almond extract; $\mathrm{AW}$ = aqueous almond extract; $\mathrm{AE}=$ almond ethyl acetate extract; $\mathrm{AC}=$ chloroform almond extract; $\mathrm{AH}=$ hexane almond extract; $\mathrm{CM}=$ methanolic cashew extract; $\mathrm{CW}=$ aqueous cashew extract; $\mathrm{CE}=$ ethyl acetate cashew extract; $\mathrm{CC}=$ chloroform cashew extract; $\mathrm{CH}=$ hexane cashew extract; $\mathrm{HM}=$ methanolic hazelnut extract; $\mathrm{HW}=$ aqueous hazelnut extract; $\mathrm{HE}=$ ethyl acetate hazelnut extract; $\mathrm{HC}=$ chloroform hazelnut extract; $\mathrm{HH}=$ hexane hazelnut extract; $\mathrm{WM}=$ methanolic walnut extract; $W W=$ aqueous walnut extract; $W E=$ ethyl acetate walnut extract; $W C=$ chloroform walnut extract; $\mathrm{WH}=$ hexane walnut extract; $\mathrm{Cis}=(50 \mathrm{mg} / \mathrm{mL})$. Results are expressed as mean \pm SEM of at least triplicate determinations. ${ }^{*}$ indicates results that are significantly different to the untreated control $(p<0.01)$.

Roswell Park Memorial Institute (RPMI) 1640 medium (Life Technologies), supplemented with $20 \mathrm{mM}$ HEPES, $10 \mathrm{mM}$ sodium bicarbonate, $50 \mu \mathrm{g} / \mathrm{mL}$ streptomycin, $50 \mathrm{IU} / \mathrm{mL}$ penicillin, $2 \mathrm{mM}$ glutamine and $10 \%$ foetal calf serum (Life Technologies). The cells were maintained as monolayers in $75 \mathrm{~mL}$ flasks at $37^{\circ} \mathrm{C}, 5 \% \mathrm{CO}_{2}$ in a humidified atmosphere until approximately $80 \%$ confluent.

\section{Evaluation of cancer cell anti-proliferative activity}

Anti-proliferation screening of $\mathrm{CaCo} 2$ carcinoma cells was performed by a modified colorimetric method. ${ }^{12,37}$ Briefly, $1 \mathrm{~mL}$ of trypsin (Sigma) was 


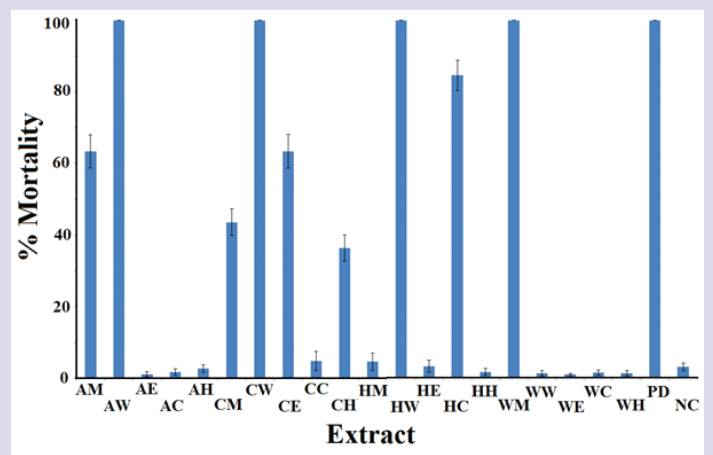

Figure 9: The lethality of the nutmeal extracts and potassium dichromate control $(1000 \mu \mathrm{g} / \mathrm{mL})$ towards Artemia franciscana nauplii after 24 hours exposure. $\mathrm{AM}=$ methanolic almond extract; $\mathrm{AW}=$ aqueous almond extract; $\mathrm{AE}=$ almond ethyl acetate extract; $\mathrm{AC}=$ chloroform almond extract; $\mathrm{AH}=$ hexane almond extract; $\mathrm{CM}=$ methanolic cashew extract; $\mathrm{CW}=$ aqueous cashew extract; $\mathrm{CE}=$ ethyl acetate cashew extract; $\mathrm{CC}=$ chloroform cashew extract; $\mathrm{CH}=$ hexane cashew extract; $\mathrm{HM}=$ methanolic hazelnut extract; $\mathrm{HW}=$ aqueous hazelnut extract; $\mathrm{HE}=$ ethyl acetate hazelnut extract; $\mathrm{HC}=$ chloroform hazelnut extract; $\mathrm{HH}=$ hexane hazelnut extract; $\mathrm{WM}=$ methanolic walnut extract; $W W=$ aqueous walnut extract; $W E=$ ethyl acetate walnut extract; $W C=$ chloroform walnut extract; $\mathrm{WH}=$ hexane walnut extract; $\mathrm{PD}=$ potassium dichromate control; NC = seawater control. Results are expressed as mean \pm SEM of at least triplicate determinations.

added to the culture flasks and incubated at $37^{\circ} \mathrm{C}, 5 \% \mathrm{CO}_{2}$ for $15 \mathrm{~min}$ to dislodge the cancer cells. The cell suspensions were then transferred to a $10 \mathrm{~mL}$ centrifuge tube and sedimented by centrifugation. The supernatant was discarded and the cells were resuspended in $9 \mathrm{~mL}$ of fresh media. Aliquots of the resuspended cells $(70 \mu \mathrm{L}$, containing approximately 5000 cells) were added to the wells of a 96 well plate. A volume of $30 \mu \mathrm{L}$ of the test extracts or cell media (for the negative control) was added to individual wells and the plates were incubated at $37^{\circ} \mathrm{C}, 5 \% \mathrm{CO}_{2}$ for 12 hours in a humidified atmosphere. A volume of $20 \mu \mathrm{L}$ of Cell Titre 96 Aqueous One solution (Promega) was subsequently added to each well and the plates were incubated for a further 3 hours. Absorbances were recorded at $490 \mathrm{~nm}$ using a Molecular Devices, Spectra Max M3 plate reader. All tests were performed in at least triplicate and triplicate controls were included on each plate. The anti-proliferative activity of each test was calculated as a percentage of the negative control using the following formula:

$$
\text { Proliferation (\% untreated control })=(A c t / A c c) \times 100
$$

$A_{c t}$ is the corrected absorbance for the test extract (calculated by subtracting the absorbance of the test extract in media without cells from the extract cell test combination) and $\mathrm{A}_{\mathrm{cc}}$ is the corrected untreated control (calculated by subtracting the absorbance of the untreated control in media without cells from the untreated cell media combination).

\section{Toxicity screening}

\section{Reference toxins for biological screening}

Potassium dichromate $\left(\mathrm{K}_{2} \mathrm{Cr}_{2} \mathrm{O}_{7}\right)$ (AR grade, Chem-Supply, Australia) was prepared as a $2 \mathrm{mg} / \mathrm{mL}$ solution in distilled water and was serially diluted in synthetic seawater for use in the A. franciscana nauplii bioassay.

\section{Artemia franciscana nauplii toxicity screening}

Toxicity was tested using a modified Artemia franciscana nauplii lethality assay. ${ }^{37-40}$ Briefly, $400 \mu \mathrm{L}$ of seawater containing approximately 54 (mean $54.3, \mathrm{n}=155, \mathrm{SD} 12.7)$ A. franciscana nauplii were added to wells of a 48 well plate and immediately used for bioassay. A volume of $400 \mu \mathrm{L}$ of diluted plant extracts or the reference toxin were transferred to the wells and incubated at $25 \pm 1^{\circ} \mathrm{C}$ under artificial light (1000 Lux). A negative control ( $400 \mu \mathrm{L}$ seawater) was run in triplicate for each plate. All treatments were performed in at least triplicate. The wells were checked at regular intervals and the number of dead counted. The nauplii were considered dead if no movement of the appendages was observed within 10 seconds. After $24 \mathrm{~h}$ all nauplii were sacrificed and counted to determine the total \% mortality per well. The $\mathrm{LC}_{50}$ with $95 \%$ confidence limits was calculated using probit analysis.

\section{Statistical analysis}

Data are expressed as the mean \pm SEM of at least three independent experiments. One way ANOVA was used to calculate statistical significance between control and treated groups with a $P$ value $<0.01$ considered to be statistically significant.

\section{RESULTS}

\section{Liquid extraction yields and qualitative phytochemical screening}

Extraction of $2 \mathrm{~g}$ of the dried nut meals with various solvents yielded dried plant extracts ranging from approximately $105 \mathrm{mg}$ (methanolic hazelnut extract) to $1477 \mathrm{mg}$ (chloroform walnut extract) (Table 1). Ethyl acetate, chloroform and hexane extracts had the highest yields of dried extracted material. Indeed, with the exception of hazelnut, these solvents generally extracted $>1000 \mathrm{mg}$ of extracted material per $2 \mathrm{~g}$ of plant material extracted ( $>50 \%$ yield). All ethyl acetate, chloroform and hexane extracts generally had substantial volumes of oils which did not completely desiccate despite extensive drying time. As these are the lower polarity solvents, it is perhaps not surprising that they extracted the greatest amounts of low polarity fats and oils. Whilst extracting lower amounts of material, the hazelnut ethyl acetate, chloroform and hexane extracts also contained large amounts of material $(650-770 \mathrm{mg})$. In contrast, the aqueous and methanolic extracts of all nuts extracted considerably lower masses $(<300 \mathrm{mg})$. The dried extracts were resuspended in $10 \mathrm{~mL}$ of deionised water resulting in the extract concentrations shown in Table 1. Phytochemical studies (Table 1) show that despite extracting lower masses, the methanolic and aqueous extracts contained the largest amount of phytochemicals screened in this study. The aqueous and methanolic extracts contained moderate to high levels of phenolics. The high level of tannins in the aqueous and methanolic walnut extracts was also noteworthy. All other phytochemical classes were either absent or only present in low levels in the aqueous and methanolic nut extracts. None of the classes of phytochemicals screened for were present in detectable levels in the ethyl acetate, chloroform and hexane extracts. However, this study concentrated on the highest polarity components and did not screen for fat and oil components. As these low polarity compounds would not be expected to be extracted into these solvents, it is likely that these extracts were rich in fats and oils.

\section{Antimicrobial activity}

To determine the growth inhibitory activity of the nutmeal extracts against the bacterial pathogens, aliquots $(10 \mu \mathrm{L})$ of each extract were tested in the disc diffusion assay. Only the almond and walnut extracts inhibited A. baylyi growth (Figure 1). The methanolic almond and walnut extracts gave the larger zones of inhibition than the other extracts (approximately 6.3 and $8 \mathrm{~mm}$ respectively). The ethyl acetate and chloroform almond extracts also inhibited A. baylyi growth, albeit with only small zones of inhibition, indicating that mid-low polarity compounds are likely to be responsible for the growth inhibitory activity. In contrast, all cashew and hazelnut extracts were completely devoid of growth inhibitory activity. When inhibitory activity was evident, the reference 
and clinical strains of A. baylyi were approximately as susceptible to the individual extracts.

Similarly, both reference and clinical strains of $E$. coli were approximately equally susceptible to the nut extracts (Figure 2). Consistent with the A. baylyi growth inhibition, E. coli also appeared more susceptible to the low-mid polarity methanolic, ethyl acetate and chloroform extracts than to the higher polarity aqueous extracts or the low polarity hexane extracts. However, in contrast to the A. baylyi growth inhibition results, the aqueous almond extract and the cashew and hazelnut hexane extracts also inhibited E. coli growth. Furthermore, E. coli growth inhibition was not limited to the almond and walnut extracts as seen for A. baylyi growth inhibition. No distinct differences were noted for the growth inhibitory efficacy between the different nut types (as determined by zones of inhibition).

K. pneumoniae growth was substantially more resistant to the nut extracts than was A. baylyi and E. coli growth (Figure 3). Indeed, only the methanolic and chloroform almond extracts, as well as the cashew chloroform extract, inhibited K. pnuemoniae growth to any degree. However, it is noteworthy that both the reference and clinical $K$. pnuemoniae strains were particularly resistant to growth inhibition. Even the ampicillin antibiotic control discs only produced relatively small zones of inhibition against both bacterial strains. This is consistent with previous studies from our laboratory which have also reported these K. pneumoniae strains to be particularly resistant to antibiotic exposure. ${ }^{27}$ Also noteworthy, the clinical K. pneumoniae strain appeared more resistant to the nut extracts and antibiotic controls than did the reference strain.

P. mirabilis (Figure 4) and P. vulgaris (Figure 5) had similar growth inhibitory profiles to A. baylyi (Figure 1). Only the almond and walnut extracts inhibited bacterial growth. The cashew and hazelnut extracts were completely devoid of growth inhibitory activity. As was evident for A. baylyi growth inhibition, the mid-low polarity methanolic, ethyl acetate and chloroform extracts were more effective growth inhibitors than were the more polar aqueous extracts, or the low polarity hexane extracts. No difference was evident between the susceptibilities of the reference and clinical $P$. mirabilis strains towards either the nut extracts, or the ampicillin control.

$P$. aeruginosa was resistant to all extracts except the methanolic and chloroform almond extracts (Figure 6). The chloroform almond extract was the most potent $P$. aeruginosa growth inhibitor (6-6.5 $\mathrm{mm}$ zones of inhibition). These small zones of inhibition are indicative of only low growth inhibitory activity. However, the almond chloroform extract was still a considerably more potent $P$. aeruginosa growth inhibitor than was the ampicillin control, indicating that both the reference and clinical $P$. aeruginosa strains are antibiotic resistant. Indeed, previous studies from our group have also shown the low susceptibility of these P. aeruginosa strains to other antibiotics. ${ }^{27,35}$

The relative level of antimicrobial activity was further evaluated by determining the MIC values (Table 2) for each extract against the bacterial species which were shown to be susceptible by disc diffusion assays. A similar trend was noted as was seen for the disc diffusion screening assays i.e. the almond and walnut extracts were generally more potent and broad-spectrum bacterial growth inhibitors than the cashew and hazelnut extracts. The methanolic walnut extract was a particularly potent growth inhibitor, with MIC values of approximately $1000 \mu \mathrm{g} / \mathrm{mL}$, $700 \mu \mathrm{g} / \mathrm{mL}$ and $800 \mu \mathrm{g} / \mathrm{mL}$ against $A$. baylyi, P. mirabilis and P. vulgaris respectively. This extract also had MIC values against $E$. coli indicative of moderate growth inhibitory activity (approximately $4500 \mu \mathrm{g} / \mathrm{mL}$ ). Potent to moderate growth inhibitory activity was also noted for the methanolic almond extract against E. coli (approximately $2000 \mu \mathrm{g} / \mathrm{mL}$ ), P. mirabilis and $P$. vulgaris (both approximately $2500 \mu \mathrm{g} / \mathrm{mL}$ ). Whilst the cashew and hazelnut extracts did not inhibit the same breadth of bacterial species as the almond and walnut extracts, the methanolic extracts of both nut meals were moderate to good inhibitors of $E$. coli growth (approximately 2500 and $1250 \mu \mathrm{g} / \mathrm{mL}$ for the cashew and hazelnut extracts respectively). All other extracts were either inactive or only low potency growth inhibitors (>5000 $\mu \mathrm{g} / \mathrm{mL}$ ) of all bacterial strains.

\section{Anti-Giardial activity}

The nutmeal extracts were screened for their ability to inhibit G. duodenalis growth (Figure 7 ). Sixteen of the 20 extracts (80\%) significantly inhibited G. duodenalis proliferation. Indeed, the methanolic almond extract was substantially more potent at inhibiting $G$. duodenalis growth than was the metronidazole control, inhibiting proliferation to approximately $5 \%$ of the untreated control growth. The methanolic cashew extract and the aqueous and ethyl acetate hazelnut extracts were also potent anti-Giardial agents, also inhibiting $G$. duodenalis proliferation to $<50 \%$ of the control growth. With the exception of the chloroform and hexane almond and cashew extracts, all other extracts had significant, albeit less potent, antiproliferative activity ( $\geq 50 \%$ of untreated control growth).

The extracts which showed $>50 \%$ inhibition of $G$. duodenalis proliferation were further tested across a range of doses to quantify and compare their efficacy (Table 2). The methanolic almond extract was a particularly potent inhibitor of $G$. duodenalis proliferation, with an $\mathrm{IC}_{50}$ of $878 \mu \mathrm{g} / \mathrm{mL}$. The aqueous and chloroform hazelnut extracts had $\mathrm{IC}_{50}$ values of 2580 and $3733 \mu \mathrm{g} / \mathrm{mL}$ respectively, which is indicative of moderate antiproliferative activity. All other extracts were either inactive or only weak inhibitors of $G$. duodenalis proliferation $(\geq 5000 \mu \mathrm{g} / \mathrm{mL})$.

\section{Inhibition of cancer cell proliferation}

The nutmeal extracts were tested against $\mathrm{CaCo} 2$ colorectal carcinoma cell, (Figure 8) to determine their ability to inhibit cancer cell growth. Interestingly, none of the extracts inhibited the proliferation of the $\mathrm{CaCo} 2$ carcinoma cells. Indeed, 15 of the 20 extracts (75\%) significantly enhanced cellular proliferation. The aqueous, chloroform and hexane almond extracts, and the methanolic, ethyl acetate and chloroform cashew extracts were particularly potent proliferarion inducers, approximately doubling $\mathrm{CaCo} 2$ proliferation compared to the untreated control. The methanolic and ethyl acetate almond extracts, the aqueous cashew extract, the methanolic, aqueous and ethyl acetate hazelnut extracts and the methanolic and aqueous walnut extracts also were good proliferative inducers, albeit with lower efficacy (generally a 20-50\% increase compared to the untreated control). All other extracts had no significant effects on $\mathrm{CaCo} 2$ proliferation.

\section{Quantification of toxicity}

The nutmeal extracts were diluted to $4000 \mu \mathrm{g} / \mathrm{mL}$ (to give a bioassay concentration of $2000 \mu \mathrm{g} / \mathrm{mL}$ ) in artificial seawater for toxicity testing in the Artemia nauplii lethality bioassay. For comparison, the reference toxin potassium dichromate was also tested in the bioassay. Potassium dichromate was rapid in its induction of mortality, with mortality evident within 4 hours of exposure (unpublished results). The nutmeal extracts were slower at inducing mortality, with $\geq 12$ hours needed for mortality induction (Figure 9). Despite the slower onset of mortality, the methanol and aqueous almond extracts, the aqueous and ethyl acetate cashew and hazelnut extracts, and the methanolic walnut extract all induced substantial mortality $(>50 \%)$, and thus were deemed toxic. All other extracts induced $<50 \%$ mortality. As toxicity of crude plant extracts has previously been defined as 24 hour $\mathrm{LC}_{50}$ values $<1000 \mu \mathrm{g} / \mathrm{ml},{ }^{38}$ the extracts which induced $<50 \%$ mortality were deemed to be nontoxic. The extracts which induced $>50 \%$ mortality were further evaluated across a range of doses to determine their $\mathrm{LC}_{50}$ values (Table 2). The $\mathrm{LC}_{50}$ values of all extracts were $>1000 \mu \mathrm{g} / \mathrm{mL}$, indicating that all of the nut extracts were nontoxic. 


\section{DISCUSSION}

Nuts are generally considered a rich source of edible fats, vitamins, proteins and fibre. Indeed, the total fat content of edible nuts is generally believed to be in the $40-75 \%$ of total nut weight range. ${ }^{41}$ This compares favourably with the contents of other foods considered to be high in dietary fats. For example, the total fat contents of Persea americana (avocado) has been estimated to be $10-25 \%$ of the total weight of the fruit. ${ }^{41}$ Whilst the levels of polyunsaturated fats are particularly high in avocado fruit, there is also a relative abundance of saturated and monounsaturated fatty acids. Indeed, the contents of lutein, tocopherol and carotenoids are amongst the highest of any commonly eaten fruit. The same study postulated that the high level of these fats is responsible for several of the therapeutic properties of avocado. In particular, it is believed that avocado fats may have anti-proliferative activity against some cancer cells. ${ }^{41}$ Further studies have demonstrated that avocado extracts inhibit the growth of LNCaP (androgen dependent) and PC-3 (androgen independent) human prostate cancer cell lines via a G2/M cell cycle arrest mechanism ${ }^{42}$ Other studies have reported that avocado extracts may also selectively induce apoptosis in oral cancer cell lines, thereby providing pleuripotent anticancer mechanisms. ${ }^{43}$ Avocado extracts also have bacterial growth inhibitory activity against Helicobacter pylori ${ }^{44}$ and inhibit selected inflammatory diseases. ${ }^{45}$

The fat content of nuts is also substantially higher than the levels in cheese ( $<35 \%$ of total mass) ${ }^{46}$ and fatty fish (generally $<5 \%$ of total mass). ${ }^{47}$ Bacterial growth inhibitory activity has been reported for these foods and it is believed that the fat content may contribute to these therapeutic effects. ${ }^{48}$ Omega- 3 fatty acids in fish oils also reduce serum triglyceride levels, thereby lessening the incidence of coronary disease. ${ }^{48}$ Similarly, coconut milk has a high fat content $(<30 \%)^{49}$ which is also believed to contribute to its antibacterial activity ${ }^{50,51}$ Furthermore, the relatively high saturated fatty acid content of coconut milk is cytotoxic to G. duodenalis trophozoites by inducing cellular rupture via mass accumulation. ${ }^{51}$ Surprisingly, despite the mounting evidence of therapeutic properties of foods with high fatty acid contents and the very high lipid content in nuts, there are relatively few studies into the therapeutic properties of edible nuts.

A recent study reported on the growth inhibitory properties of $M$. integrifolia nut extracts on a panel of pathogenic and food spoilage microbes. ${ }^{15}$ E. coli and P. mirabilis were particularly susceptible to the methanolic macadamia extracts, with MIC values of 8 and $11 \mu \mathrm{g} / \mathrm{mL}$ respectively. The ethyl acetate macadamia extract was also a particularly potent bacterial growth inhibitor, with MIC values of 34 and $13 \mu \mathrm{g} / \mathrm{mL}$ against E. coli and $P$. mirabilis respectively. The same study reported very low anti-Giardial $\mathrm{IC}_{50}$ values $(<10 \mu \mathrm{g} / \mathrm{mL})$ for the macadamia extracts, indicating that the macadamia extracts may prove useful in the treatment of giardiasis. Furthermore, the macadamia nut extracts inhibited proliferation of the choriocarcinoma cell line Jeg-3 with $\mathrm{IC}_{50}$ values $<1000 \mu \mathrm{g} / \mathrm{mL}$ for all extracts. The authors of that study postulated that the high fat content of macadamia nuts may contribute to these therapeutic bioactivities.

Our study demonstrates that some of the almond, cashew, hazelnut and walnut extracts had similar, albeit less potent, bioactivities as those reported in the macadamia study. Generally, almond and walnut extracts inhibited the growth of the broadest range of the bacterial tested. Cashew and almond extracts generally only inhibited E. coli growth. In contrast, almond and walnut extracts inhibited the growth of $100 \%$ and 7 of the $11(64 \%)$ of the bacterial strains tested respectively. The methanolic walnut extract was a particularly potent growth inhibitor, with MIC values of approximately 1000, 700 and $800 \mu \mathrm{g} / \mathrm{mL}$ against A. baylyi, P. mirabilis and $P$. vulgaris respectively. The growth inhibitory activity towards $P$. mirabilis is particularly noteworthy as this bacterium has been implicated in urinary tract infections (UTI's) and the induction of rheumatoid arthritis
(RA) ${ }^{52}$ Thus, the methanolic walnut extract has potential treatment has the potential to block RA before the induction of the immune response and inflammation, thus not only blocking the late phase symptoms, but also the tissue damage associated with RA. Similarly, as A. baylyi has been proposed as a microbial trigger of multiple sclerosis, ${ }^{27,35}$ the methanolic walnut extract may also be useful in preventing on onset of this disease in genetically susceptible individuals.

Potent growth inhibition of the food/water borne gastrointestinal parasite Giardia duodenalis was also noted for the methanolic almond nut extract in our study. Giardial infection (giardiasis) is a re-emerging disease which afflicts large numbers of individuals worldwide, with higher incidence in countries with poorer socio-economic conditions, inadequate sanitary conditions, untreated water supplies and poor diet. ${ }^{51}$ Whilst generally not fatal, giardiasis results in debilitating symptoms including bloating, diarrhoea, excess gas, loss of appetite, loose and watery stool, stomach cramps and haematuria. Currently, there are only a narrow range of drugs effective against giardiasis, including quinalones and imidazole derivatives. None of these drugs is ideal as they produce unpleasant side effects including nausea, vertigo, vomiting, diarrhoea and hallucinations. ${ }^{51,53}$ Furthermore, increasing reports of the failure of current treatments to address this disease indicates a developing drug resistance of several Giardia species. ${ }^{53}$ Recent studies have highlighted the potential of functional foods and have demonstrated that some food components, particularly medium chain saturated fatty acids, are very effective inhibitors of Giardia duodenalis growth with similar potency to the gold standard drug metranidazole. ${ }^{51}$ That study also showed that these fatty acids killed the Giardial parasite by accumulating in the cell, resulting in membrane rupture. It is therefore possible that the inhibition of Giardia duodenalis growth by the methanolic almond extract reported in our study may also be due to cell rupture due to fatty acid accumulation within the protozoan cytoplasm.

Interestingly, no inhibition of $\mathrm{CaCo} 2$ carcinoma proliferation was noted in our study. Indeed, the majority of the nut extracts induced a substantial increase in $\mathrm{CaCo} 2$ proliferation to approximately double the levels of the untreated control. This contrasts with the previous macadamia nut study which reported potent anti-proliferative activity against Jeg-3 choriocarcinoma cells. ${ }^{15}$ It is unknown whether these differences are related to the different cell lines tested as the Jeg- 3 cell line screened in the macadamia study has been reported to produce high levels of thioredoxin ${ }^{54}$ which may affect progression through the cell cycle and/or apoptosis induction. Further testing in a panel of carcinoma cell lines (including Jeg- 3 cells) as well as normal cell lines is warranted. If a similar trend is noted as seen for the $\mathrm{CaCo} 2$ cells, this would impact on the therapeutic usefulness of these extracts for cancer patients. Indeed, a further enhancement of proliferation by the nut extracts would be detrimental in cancer patients and instead is likely to hasten the disease progression. However, if a similar proliferative trend is noted in normal cell lines, this may indicate a different therapeutic use for the extracts, in speeding and enhancing wound healing. This would be a particularly useful property for the treatment of cuts, abrasions and burns and this requires further testing.

The results of this study indicate that the almond and walnut extracts examined in this report are worthy of further study due to their antibacterial and anti-Giardial activities and ability to enhance cellular proliferation. Furthermore, the findings reported here also show that all nut extracts were nontoxic towards $A$. franciscana, with $\mathrm{LC}_{50}$ values substantially $>1000 \mu \mathrm{g} / \mathrm{mL}$. Extracts with $\mathrm{LC}_{50}$ values greater than $1000 \mu \mathrm{g} / \mathrm{mL}$ in the Artemia nauplii bioassay have previously been defined as being non-toxic. ${ }^{38}$ However, further toxicity studies using human cell lines are needed to further determine the suitability of the nut extracts for medicinal purposes. Likewise, bioactivity driven purification studies are required to examine the mechanisms of action of these agents. 


\section{CONCLUSION}

The results of this study highlight the potential of almond and walnut extracts to treat bacterial and protozoal diseases and indicate that they warrant further study. Bioactivity driven purifications of the active components and an examination of the mechanisms of action of these agents is required.

\section{ACKNOWLEDGEMENTS}

We are grateful to Professor Andre Buret for the kind gift of the G. duodenalis trophozoites used in this study. Financial support for this work was provided by the Environmental Futures research Institute and the School of Natural Sciences, Griffith University.

\section{CONFLICTS OF INTEREST}

The authors report no conflicts of interest.

\section{ABBREVIATIONS USED}

DMSO: Dimethyl sulfoxide; $\mathbf{I C}_{50}$ : The concentration required to achieve a $50 \%$ reduction of the untreated value; $\mathbf{L C}_{50}$ : The concentration required to achieve 50\% mortality; MIC: Minimum inhibitory concentration.

\section{REFERENCES}

1. Tapsell LC, Hemphill I, Cobiac L, et al. Health benefits of herbs and spices: the past, the present, the future. Medical Journal of Australia. 2006;185(4):S1-24

2. Anand $P$, Sundaram $C$, Jhurani $S$, et al. Curcumin and cancer: an "old-age" disease with an "age-old" solution. Cancer Letters. 2008;267(1):133-64.

3. Karalliedde L, Gawarammana I. Traditional herbal medicines. Hammersmith Press 2008; London UK.

4. Maen A, Cock IE. Inhibitory activity of Australian culinary herb extracts against the bacterial triggers of selected autoimmune diseases. Pharmacognosy Communications. 2015;5(2):130-9. DOI: 10.5530/pc.2015.2.4

5. Winnett $\mathrm{V}$, Boyer H, Sirdaarta J, et al. The potential of Tasmannia lanceolata as a natural preservative and medicinal agent: Antimicrobial activity and toxicity. Pharmacognosy Communications. 2014;4(1):42-52. DOI: 10.5530/pc.2014.1.7

6. Cock IE, Mohanty S. Evaluation of the antibacterial activity and toxicity of Terminalia ferdinandia fruit extracts. Pharmacognosy Journal. 2011;3(20):72-9. DOI: 10.5530/pj.2011.20.14

7. Sautron C, Cock IE. Antimicrobial activity and toxicity of Syzygium australe and Syzygium leuhmanii fruit extracts. Pharmacognosy Communications. 2014;4(1):53-60. DOI: 10.5530/pc.2014.1.8

8. Wright M, Matthews B, Greene A, et al. Growth inhibition of the zoonotic bacteria Bacillus anthracis by high antioxidant Australian plants: New leads for the prevention and treatment of anthrax. Pharmacognosy Communications 2015;5(3):173-89. DOI: 10.5530/pc.2015.3.3

9. Sirdaarta J, Matthews B, Cock IE. Kakadu plum fruit extracts inhibit growth of the bacterial triggers of rheumatoid arthritis: Identification of stilbene and tannin components. Journal of Functional Foods. 2015;17:610-20. DOI: 10.1016/ jff.2015.06.019

10. Rayan P, Matthews B, McDonnell PA, et al. Terminalia ferdinandiana extracts as inhibitors of Giardia duodenalis proliferation: a new treatment for giardiasis. Parasitology Research. 2015;114(7):2611-20. DOI: 10.1007/s00436-015-4465-4

11. Rayan P, Matthews B, McDonnell PA, et al. Phytochemical analysis of Tasmannia lanceolata extracts which inhibit Giardia duodenalis proliferation. Pharmacognosy Magazine. 2016;8(3):291-9. DOI: 10.5530/pj.2016.3.19

12. Jamieson N, Sirdaarta J, Cock IE. The anti-proliferative properties of Australian plants with high antioxidant capacities against cancer cell lines. Pharmacognosy Communications. 2014;4(4):71-82. DOI: 10.5530/pc.2014.4.8

13. Desegaulx M, Sirdaarta J, Rayan $P$, et al. An examination of the antibacterial, anti-fungal, anti-Giardial, and anti-cancer properties of Macadamia nut. Acta Horticulturae 2016; in press.

14. Boyer $\mathrm{H}$, Cock IE. Evaluation of the potential of Macademia integriflora extracts as antibacterial food agents. Pharmacognosy Communications. 2013; 3(3):53-62. DOI: 10.5530/pc.2013.3.10

15. Cock IE. Antibacterial activity of selected Australian native plant extracts. Internet Journal of Microbiology. 2008;4(2):1-8.

16. Akhtar N, Ahmad M, Madni A, et al. Evaluation of the basic properties of Macadamia nut oil. Gomal University Journal of Research. 2006;22(1):21-7.

17. Garg ML, Blake RJ, Wills RBH. Macadamia nut consumption lowers plasma total and LDL cholesterol levels in hypercholesterolemic men. The Journal of Nutrition. 2003;133(4):1060-3.
18. Ken K. Kukui and Macadamia nut oil. Cosmetics and Toiletries. 1991;160(11):87-90.

19. López-Ortiz CM, Prats-Moya S, Sanahuja AB, et al. Comparative study of tocopherol homologue content in four almond oil cultivars during two consecutive years. Journal of Food Composition and Analysis. 2008;21(2):144-51.

20. Maguire LS, O'Sullivan SM, Galvin K, et al. Fatty acid profile, tocopherol, squalene and phytosterol content of walnuts, almonds, peanuts, hazelnuts and the macadamia nut. International Journal of Food Sciences and Nutrition. 2004;55(3):171-8

21. Kris-Etherton PM, Pearson TA, Wan $Y$, et al. High monounsaturated fatty acid diets lower both plasma cholesterol and triacylglycerol concentrations. American Journal of Clinical Nutrition. 1999;70(6):1009-15.

22. Ozge C, Gokmen V, Pellegrini N, et al. Direct evaluation of the total antioxidant capacity of raw and roasted pulses, nuts and seeds. European Food Research and Technology. 2009;229(6):961-9.

23. Ryan E, Galvin K, O'Connor TP, et al. Fatty acid profile, tocopherol, squalene and phytosterol content of brazil, pecan, pine, pistachio and cashew nuts. International Journal of Food Sciences and Nutritiuon. 2006;57(3-4):219-28.

24. United States Department of Agriculture Agricultural Research Service National nutrient database for standard reference release 28; http://ndb.nal usda.gov/ndb/foods/show $/ 3720 ? \mathrm{fg}=\& \mathrm{man}=\& \mid \mathrm{facet}=\&$ count $=\& \mathrm{max}=35 \&$ sort $=\&$ qlookup $=$ walnuts \&offset $=\&$ format $=$ Full \&new $=\&$ measureby $=:$ accessed 4 January 2016

25. Cock IE. The phytochemistry and chemotherapeutic potential of Tasmannia lanceolata (Tasmanian pepper): a review. Pharmacognosy Communications. 2013;3(4):13-25. DOI: 10.5530/pc.2013.4.3

26. Vesoul J, Cock IE. An examination of the medicinal potential of Pittosporum phylloraeoides: Toxicity, antibacterial and antifungal activities. Pharmacognosy Communications. 2011;1(2):8-17. DOI: 10.5530/pc.2011.2.1

27. Courtney R, Sirdaarta J, Matthews B, et al. Tannin components and inhibitory activity of Kakadu plum leaf extracts against microbial triggers of autoimmune inflammatory diseases. Pharmacognosy Journal. 2015;7(1):18-31. DOI: 10.5530/pj.2015.7.2

28. Cock IE, Kukkonen L. An examination of the medicinal potential of Scaevola spinescens: Toxicity, antibacterial, and antiviral activities. Pharmacognosy Research. 2011;3(2):85-94. DOI: 10.4103/0974-8490.81955

29. Cock IE, Winnett V, Sirdaarta J, et al. The potential of selected Australian medicinal plants with anti-Proteus activity for the treatment and prevention of rheumatoid arthritis. Pharmacognosy Magazine. 2015;11(42 Suppl):S190-208. DOI: 10.4103/0973-1296.157734

30. Kalt FR, Cock IE. GC-MS analysis of bioactive Petalostigma extracts: Toxicity, antibacterial and antiviral activities. Pharmacognosy Magazine. 2014;10(37 Suppl): S37-49. DOI: 10.4103/0973-1296.127338

31. Chikowe G, Mpala L, Cock IE. Antibacterial activity of selected Australian Syzygium species. Pharmacognosy Communications. 2013;3(4):77-83. DOI: 10.5530/ pc.2013.4.11

32. Mohanty S, Cock IE. Bioactivity of Syzygium jambos methanolic extracts: antibacterial activity and toxicity. Pharmacognosy Research. 2010;2(1):4-9.

33. Cock IE. Antimicrobial activity of Eucalyptus major and Eucalyptus baileyana methanolic extracts. Internet Journal of Microbiology. 2009;6(1).

34. Cock IE, van Vuuren SF. The potential of selected South African plants with antiKlebsiella activity for the treatment and prevention of ankylosing spondylitis. Inflammo Pharmacology. 2015;23(1):21-35. DOI: 10.1007/s10787-014-0222-z

35. Sirdaarta J, Matthews B, White A, et al. GC-MS and LC-MS analysis of Kakadu plum fruit extracts displaying inhibitory activity against microbial triggers of multiple sclerosis. Pharmacognosy Communications. 2015;5(2):100-15. DOI 10.5530/pc. 2015.2.2

36. Arkhipov A, Sirdaarta J, Rayan $P$, et al. An examination of the antibacterial, antifungal, anti-Giardial and anticancer properties of Kigelia africana fruit extracts. Pharmacognosy Communications. 2014;4(3):62-76. DOI: 10.5530/pc.2014.3.7

37. Arkhipov A, Sirdaarta J, Matthews B, et al. Metabolomic profiling of Kigelia africana extracts with anti-cancer activity by high resolution tandem mass spectroscopy. Pharmacognosy Communications. 2014:4(4):10-32. DOI: 10.5530/ pc.2014.4.3

38. Cock IE, Ruebhart DR. Comparison of the brine shrimp nauplii bioassay and the ToxScreen-II Test for the detection of toxicity associated with Aloe vera (Aloe barbadensis Miller) leaf extract. Pharmacognosy Research. 2009;1(2):98101.

39. Ruebhart DR, Wickramasinghe W, Cock IE. Protective efficacy of the antioxidants vitamin $\mathrm{E}$ and Trolox ${ }^{\mathrm{TM}}$ against Microcystis aeruginosa, microcystin-LR and menadione toxicity in Artemia franciscana nauplii. Journal of Toxicology and Environmental Health Part A. 2009:72(24):1567-75.

40. Sirdaarta J, Cock IE. Vitamin E and Trolox ${ }^{\mathrm{TM}}$ reduce toxicity of Aloe barbadensis Miller juice in Artemia franciscana nauplii but individually are toxic at high concentrations. Internet Journal of Toxicology. 2008;5(1).

41. Lu QY, Zhang $Y$, Wang $Y$, et al. California Hass avocado: Profiling of carotenoids, tocopherol, fatty acid, and fat content during maturation and from different growing areas. Journal of Agricultural and Food Chemistry. 2009;57(21):10408-13.

42. Lu QY, Arteaga JR, Zhang Q, et al. Inhibition of prostate cancer cell growth by 
an avocado extract: Role of lipid-soluble bioactive substances. Journal of Nutritional Biochemistry. 2005;16(1):23-30.

43. Ding H, HanC, Guo D, et al. Selective induction of apoptosis of human oral cancer cell lines by avocado extracts via a ROS-mediated mechanism. Nutrition and Cancer. 2009;61(3):348-56.

44. Castillo-Juarez I, Gonzales V, Jaime-Aguilar H, et al, Anti-Helicobacter pylor activity of plants used in Mexican traditional medicine for gastrointestinal disorders. Journal of Ethnopharmacology. 2009;122(2):402-5.

45. Ding $H$, Chin YW, Kinghorn AD, et al. Chemopreventative characteristics of avocado fruit. Seminars in Cancer Biology. 2007;17(5):386-94.

46. Gwartney EA, Foegeding EA, Larick DK. The texture of commercial full-fat and reduced-fat cheese. Journal of Food Science. 2002;67(2):812-6.

47. Iverson SJ, Frost KJ, Lang LC. Fat content and fatty acid composition of forage fish and invertebrates in Prince William Sound, Alaska: factors contributing to among and within species variability. Marine Ecology Progress Series. 2002;:241:161-81.

48. Wohl DA, Tien HC, Busby M, et al. Randomized study of the safety and efficacy of fish oil (omega-3 fatty acid) supplementation with dietary and exercise counselling for the treatment of antiretroviral therapy-associated hypertrigly ceridemia.
Clinical Infectious Diseases. 2005;41(10):1498-504.

49. Simuang J, Chiewchan N, Tansakul A. Effects of fat content and temperature on the apparent viscosity of coconut milk. Journal of Food Engineering. 2004;64(2):193-7.

50. Verallo-Rowell VM, Dillague KM, Syah-Tjundawan BS. Novel antibacterial and emollient effects of coconut and virgin olive oils in adult atopic dermatitis. Dermatitis. 2008;19(6):308-15

51. Rayan P, Stenzel D, McDonnell PA. The effects of saturated fatty acids on Giardia duodenalis trophozoites in vitro. Parasitology Research. 2005;97(3):191200.

52. Cock IE, van Vuuren SF. Anti-Proteus activity of some South African medicinal plants: Their potential for the prevention of rheumatoid arthritis. Inflammo Pharmacology. 2014;22(1):23-36. DOI: 10.1007/s10787-013-0179-3

53. Harris JC, Plummer S, Lloyd D. Anti-giardial drugs. Applied Microbiology and Biotechnology. 2001;57(5-6):614-9.

54. Di Trapani G, Perkins A, Clarke F. Production and secretion of thioredoxin from transformed human trophoblast cells. Molecular Human Reproduction. 1998;4(4): 369-75

\section{PICTORIAL ABSTRACT}

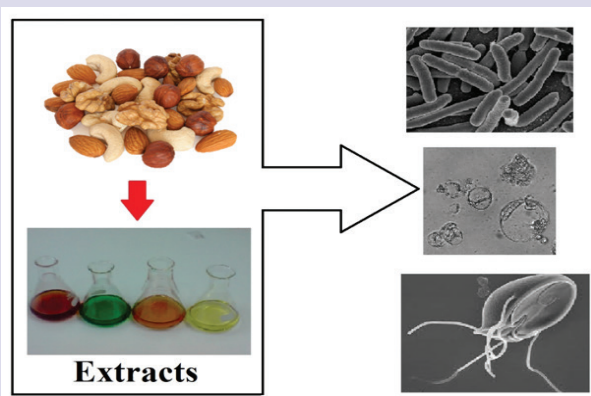

\section{SUMMARY}

- The methanolic walnut extract was a potent bacterial growth inhibitor, with $\mathrm{MIC} \leq 1000 \mu \mathrm{g} / \mathrm{mL}$ against $A$. baylyi, $P$. mirabilis and $P$. vulgaris.

- The methanolic almond extract also had moderate inhibitory activity against $E$. coli, P. mirabilis and $P$. vulgaris with $\mathrm{MIC} \leq 2500 \mu \mathrm{g} / \mathrm{mL}$.

- The methanolic almond extract was also a potent inhibitor of Giardia duodenalis proliferation $\left(\mathrm{IC}_{50} 878 \mu \mathrm{g} / \mathrm{mL}\right)$.

- All of the nut extracts were non-toxic in the Artemia nauplii assay.

\section{ABOUT AUTHOR}

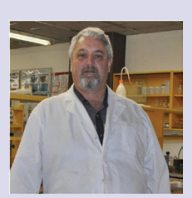

Dr lan Cock: Leads a research team in the Environmental Futures Research Institute and the School of Natural Sciences at Griffith University, Australia. His research involves bioactivity and phytochemical studies into a variety of plant species of both Australian and international origin, including Aloe vera, South Asian and South American tropical fruits, as well as Australia plants including Scaevola spinescens, Pittosporum phylliraeoides, Terminalia ferdinandiana (Kakadu plum), Australian Acacias, Syzygiums, Petalostigmas and Xanthorrhoea johnsonii (grass trees). This range of projects has resulted in nearly 200 publications in a variety of peer reviewed journals. 